$$
\text { NACW-35/9 }
$$

\title{
The thermal and radiation exposure history of lunar meteorites
}

\author{
PAUl H. BENOIT*, DEREK W. G. SEARS AND STEVEN J. K. SYMES
}

Cosmochemistry Group, Department of Chemistry and Biochemistry, University of Arkansas, Fayetteville, Arkansas 72701 USA

*Correspondence author's e-mail address: cosmo@uafsysb.uark.edu

(Received 1995 December 15; accepted in revised form 1995 June 17)

(Submitted as part of a series of papers on Queen Alexandra Range 93069 and other lunar meteorites)

\begin{abstract}
We have measured the natural and induced thermoluminescence (TL) of seven lunar meteorites in order to examine their crystallization, irradiation, and recent thermal histories. Lunar meteorites have induced TL properties similar to Apollo samples of the same provenance (highland or mare), indicating similar crystallization and metamorphic histories. MacAlpine Hills 88104/5 has experienced the greatest degree of impact/regolith processing among the highland-dominated meteorites. The basaltic breccia QUE 94281 is dominated by mare component but may also contain a significant highland component. For the mare-dominated meteorites, EET 87521 may have a significant highland impact-melt component, while Asuka 881757 and Y-793169 have been heavily shocked. The thermal history of Y-793169 included slow cooling, either during impact processing or during its initial crystallization. Our natural TL data indicate that most lunar meteorites have apparently been irradiated in space a few thousand years, with most $<15,000$ a. Elephant Moraine 87521 has the lowest irradiation exposure time, being $<1,000$ a. Either the natural TL of ALHA81005, Asuka 881757 and Y-82192 was only partially reset by lunar ejection or these meteorites were in small perihelia orbits ( $\leq 0.7 \mathrm{AU})$.
\end{abstract}

\section{INTRODUCTION}

The lunar meteorites offer new insights into the origin and evolution of the Moon, providing about a dozen new study localities possibly including the lunar farside (Warren and Kallemeyn, 1991). In this paper, we examine the thermal and irradiation history of lunar meteorites in comparison to Apollo samples using thermoluminescence.

Thermoluminescence is energy cmitted as photons from a sample during heating. This energy is typically deposited by ionizing radiation. Natural thermoluminescence (natural TL) reflects recent thermal history and irradiation conditions (Hoyt et al., 1971; Durrani et al., 1977; Sears et al, 199 Ia). In the case of lunar meteorites, natural TL is related primarily to preimpact depth in the regolith, duration of cosmic-ray irradiation, and temperatures experienced in space (Sutton, 1986; Sutton and Crozaz, 1983; Sears et al., 1991a). Sutton (1986) and Sutton and Crozaz (1983) have examined the natural TL of ALHA81005 and Y-82192, suggesting that Y-82192 was in an orbit with a small perihelia and ALHA81005 was in space for only a few thousand years. The natural TL of lunar samples and meteorites is also affected by a process known as anomalous fading, which results in TL being lowered at rates much faster than predicted from thermal equilibria alone (Sears et al., 1991a).

Induced thermoluminescence is the TL produced in a sample after removing the natural TL by momentary heating to $\sim 500^{\circ} \mathrm{C}$ followed by laboratory irradiation. Unlike natural TL, features in the induced TL glow curve directly reflect bulk properties of TL phosphors. The induced thermoluminescence intensity at peak emission (induced TL sensitivity) reflects the composition, structure and abundance of the phosphors, primarily feldspar (Sippel and Spencer, 1971; Geake et al., 1977; Symes et al., 1995). The peak temperature of the induced TL of feldspar is related to mineral structure, with ordered feldspar having significantly lower peak temperatures than disordered feldspar (Guimon et al., 1985; Hartmetz and Sears, 1987). We have previously used induced TL properties to examine the metamorphic and brecciation histories of most meteorite classes and a wide variety of lunar samples (e.g., Haq et al., 1989; Sears et al., 1991b; Batchelor and Sears, 1991; Guimon et al., 1995)

In the present study, we summarize the natural and induced properties of seven lunar meteorites. We interpret the induced TL data in the context of crystallization and impact processing, and we interpret natural TL data in terms of recent irradiation and lowtemperature thermal history.

\section{METHODS}

The samples, their sources, and simple descriptions are given in Table 1. Our samples were chips of $-300 \mathrm{mg}$. We crushed $\sim 150 \mathrm{mg}$ of each sample to 100 mesh using an agate mortar and placed three $4 \mathrm{mg}$ aliquots in shallow $\mathrm{Cu}$ pans. Their natural TL was measured by heating in a $\mathrm{N}$ atmosphere to $500^{\circ} \mathrm{C}$ at $7.5^{\circ} \mathrm{C} / \mathrm{s}$ using a Daybreak Nuclear and Medical Systems $T L$ apparatus fitted with blue bandpass and IR filters (Coming 7-59 and 4-69). The induced TL was measured by the same procedure $5 \mathrm{~min}$ after exposure to a $\sim 2 \mathrm{krad}$ beta dose from a ${ }^{90} \mathrm{Sr}$ source. The Dhajala metcorite was used as a normalization standard and long-term check on the apparatus. We report TL sensitivity normalized to the Dhajala standard and peak temperatures. For natural TL data, we report equivalent dose at $250^{\circ} \mathrm{C}$ and $400^{\circ} \mathrm{C}$ in the glow curve (Sears and Hasan, 1986).

The anomalous fading characteristics of the highland meteorite Y-82192, the mare basalt EET 87521 , and QUE 94281 were determined using a $4 \mathrm{mg}$ sample which had been drained, irradiated, and stored in opaque containers in a dessicator in a temperature-controlled room for up to several weeks. The fading properties of ALHA76008 (H6) and highland soil 61501 were deternined in the same way.

\section{RESULTS}

Our data are summarized in Table 1. Analytical uncertainties on both natural and induced TL data are quite small (generally $<5 \%$ ) despite the generally low levels, which in the case of EET 87521 and Asuka 881757 approach detection limits. The reproducibility of the data for the ALHA81005 and EET 87521 splits is well within analytical uncertainties. The data for MAC 88104 and MAC 88105 differ by more than the experimental uncertainties, although they are paired. As discussed below, these differences reflect real heterogeneities in the meteorite. We did not have duplicate chips of the remaining meteorites and cannot comment on possible heterogenities, but our conclusions are generally consistent with those based 
TABLE I. Induced and natural thermoluminescence properties of lunar meteorites.

\begin{tabular}{|c|c|c|c|c|c|c|c|}
\hline Meteorite* & $\begin{array}{l}\text { Mass } \\
(\mathrm{mg})\end{array}$ & $\begin{array}{c}\text { Induced TL } \\
\text { Sensitivity } \\
\text { (Dhajala = I) }\end{array}$ & $\begin{array}{c}\text { Peak } \\
\text { Temp }\left({ }^{\circ} \mathrm{C}\right)\end{array}$ & \multicolumn{2}{|c|}{$\begin{array}{l}\text { Natural TL } \\
(\mathrm{krad})\end{array}$} & $\begin{array}{c}\text { Terrestrial } \\
\text { Age } \\
(\mathrm{ka})^{\ddagger}\end{array}$ & Description $\$$ \\
\hline & & & & & & & \\
\hline $\begin{array}{l}\text { ALHA8 } 1005,83 \\
\text { ALHA } 81005,84\end{array}$ & $\begin{array}{l}62 \\
56\end{array}$ & $\begin{array}{l}0.22 \pm 0.02 \\
0.24 \pm 0.04\end{array}$ & $\begin{array}{l}167 \pm 6 \\
169 \pm 6\end{array}$ & $\begin{array}{l}0.10 \pm 0.02 \\
0.11 \pm 0.02\end{array}$ & $\begin{array}{l}5 \pm 1 \\
9 \pm 1\end{array}$ & $15 \pm 6$ & Anorthositic regolith breccia-Highland \\
\hline A 881757,70 & 403 & $0.003 \pm 0.002$ & $\begin{array}{l}169 \pm 6 \\
195 \pm 5\end{array}$ & $\sim 0$ & -20 & & \\
\hline EET 87521,36 & 25 & $0.038 \pm 0.003$ & $218 \pm 4$ & $0.11 \pm 0.02$ & $\sim 0.5$ & $\begin{array}{l}25 \pm 25 \\
20 \pm 20\end{array}$ & $\begin{array}{l}\text { Unbrecciated gabbro-Mare } \\
\text { Basaltic breccia-Mare }\end{array}$ \\
\hline EET 87521,40 & 51 & $0.040 \pm 0.003$ & $210 \pm 3$ & $0.13 \pm 0.01$ & $0.6 \pm 0.1$ & $20 \pm 20$ & \\
\hline MAC $88104,2^{\dagger}$ & 326 & $0.137 \pm 0.004$ & $197 \pm 4$ & $2.5 \pm 0.3$ & $7.1 \pm 0.2$ & $230 \pm 70$ & Anorthositic regolith breccia-Highland \\
\hline MAC $88105,4^{\dagger}$ & 270 & $0.128 \pm 0.009$ & $172 \pm 4$ & $1.1 \pm 0.1$ & $11 \pm 2$ & $230 \pm 70$ & \\
\hline QUE 94281,13 & 102 & $0.056 \pm 0.004$ & $171 \pm 2$ & $0.21 \pm 0.01$ & $1.0 \pm 0.1$ & & Basalt-rich breccia \\
\hline Y793169,56 & 21 & $0.0050 \pm 0.0003$ & $171 \pm 6$ & $1.4 \pm 0.2$ & $4 \pm 2$ & $25 \pm 25$ & $\begin{array}{l}\text { Basalt-rich breccia } \\
\text { Unbrecciated diabase-Mare }\end{array}$ \\
\hline Y82192,64 & 214 & $0.27 \pm 0.02$ & $164 \pm 3$ & $3.6 \pm 0.9$ & $20 \pm 7$ & $80 \pm 20$ & $\begin{array}{l}\text { Unbrecciated diabase-Mare } \\
\text { Anorthositic fragmental breccia-Highland }\end{array}$ \\
\hline
\end{tabular}

Uncertainties are the standard deviations shown by replicate measurements of a single aliquot.

Uncerainties are the standard deviations shown by repterite Working Group of NASA, *Asuka and Yamato samples were obtained from K. Yanai (Nat. Institute Polar Rese Elephant Moraine; MAC = MacAlpine Hills; QUE = Qucen Alexandra Johnson Space Center.

Range; $\mathrm{Y}=$ Yamato.

†MAC 88104 and MAC 88105 are probably paired (Lindstrom, 1989)

¥From Nishiizumi (per. comm.)

SFrom Yanai and Kojima (1991) and Mason (1995).

on petrographic data, suggesting that heterogenity is not a major problem.

We compare the induced TL data for lunar meteorites with data for Apollo samples in Fig. Ia. The Apollo data from Batchelor (1992) are shown as fields. The lunar meteorites have a smaller range of induced TL peak temperature than Apollo lunar samples, with no lunar meteorites having peak temperatures $<160^{\circ} \mathrm{C}$. Also, the lunar meteorites have TL sensitivities comparable to Apollo samples. The lunar highland meteorites have TL sensitivity levels similar to those of Apollo highland samples while the lunar mare meteorites have sensitivities similar to the Apollo mare samples.

The natural TL levels of lunar meteorites are best compared to basaltic meteorites rather than Apollo samples, since the Apollo samples were not irradiated in $4 \pi$ geometry and therefore experienced a lower radiation dose rate. The basaltic meteorites have luminescence properties very similar to lunar meteorites, including the presence of anomalous fading. The lunar meteorites have low TL levels compared to most Antarctic basaltic meteorites at 250 and $400{ }^{\circ} \mathrm{C}$ in the glow curve (Fig. 2a,b). Both lunar and basaltic meteorites have TL levels lower than those of most ordinary chondrites by a factor of ten or more.

The results of the anomalous fading experiments are shown in Fig. 3. The intensity of TL at three temperatures in the glow curve are normalized to the TL level at the same glow curve temperatures measured five minutes after irradiation. The two lunar meteorites and the highland soil sample exhibit anomalous fading. They also have the same fading rates, within the experimental uncertainties, as is evidenced by the variation between replicates. The ordinary chondrite does not display anomalous fading, the loss of signal occurring at the lowest glow curve temperatures and the longest time periods being due to normal thermal fading, in accord with models of TL thermal decay (McKeever, 1980). The rates of fading for the lunar samples are similar to those noted for ALHA81005 (Sutton and Crozaz, 1983) and terrestrial feldspars (Wintle, 1973).

\section{DISCUSSION}

\section{Induced TL Properties of Lunar Meteorites}

The induced TL of most lunar samples can be interpreted in terms of mixtures of pristine highland material, highland impact melt rocks, and mare material (Symes et al., 1995; Fig. 1b) and in
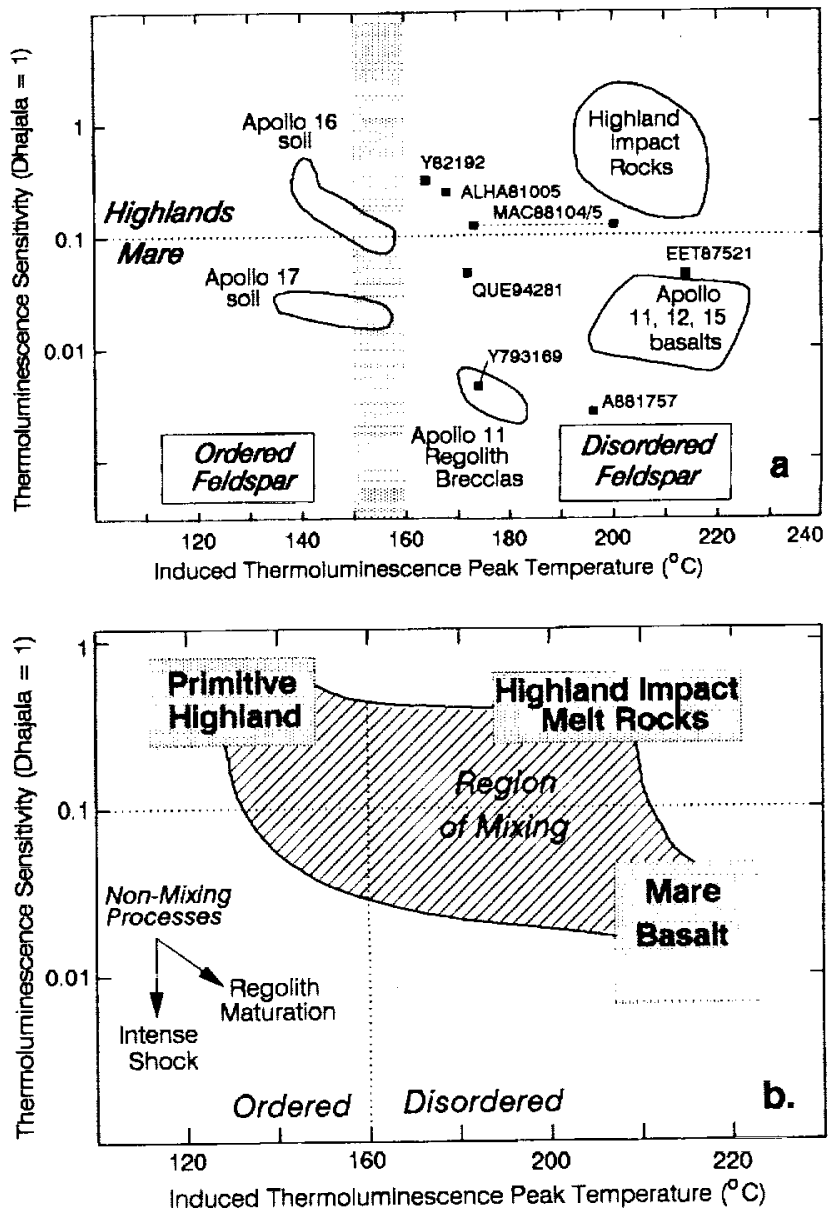

FIG 1. (a) Induced TL sensitivity $v s$. peak temperature for lunar meteorites and Apollo samples. Lunar meteorites generally resemble their closest petrographic analogs in the Apollo collection, highland-dominated samples paving high TL sensitivity and mare-dominated samples having low TL sensitivity and high TL peak temperatures. Fields for Apollo samples based on data of Batchelor (1992). (b) Schematic diagram of the luminescent "components" in lunar samples and possible mixing curves. Thermoluminescence sensitivity reflects the abundance and crystallinity of feldspar while TL peak temperature reflect its degree of structural order. Arrows indicate the effects of processes other than mixing in this diagram. 


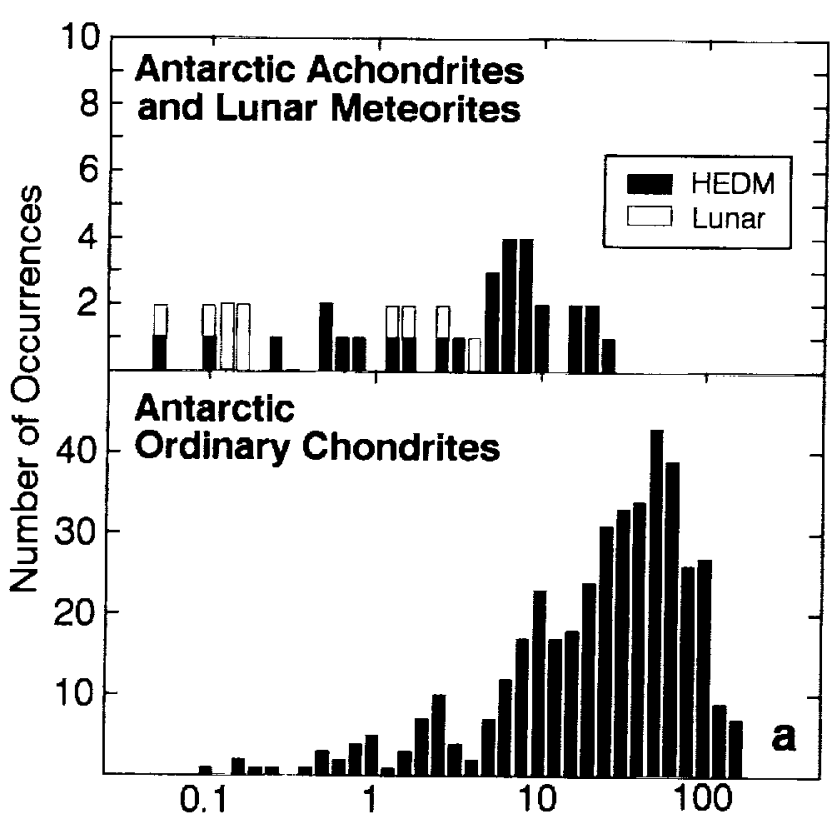

Natural Thermoluminescence at $250^{\circ} \mathrm{C}(\mathrm{krad})$

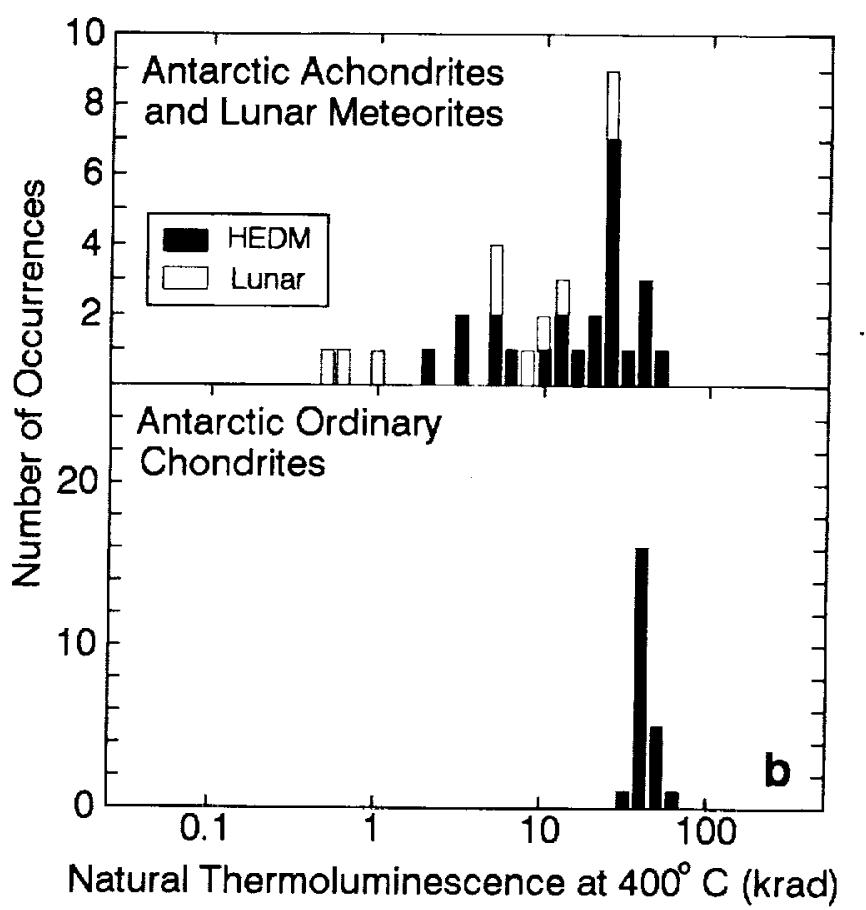

FIG. 2. Natural TL levels of lunar meteorites, basaltic achondrites (HEDM: howardites, eucrites, diogenites, and mesosiderites), and ordínary chondrites at (a) $250^{\circ} \mathrm{C}$ and (b) $400^{\circ} \mathrm{C}$ in the glow curve. Lunar meteorites and basaltic meteorites generally have lower natural TL levels than ordinary chondrites, and lunar meteorites have TL levels in the low TL tail of the distribution.

terms of thermal processes. Intense shock lowers TL sensitivity considerably by fusing the feldspar while regolith processing results in slightly lower TL sensitivity and moderate increases in induced TL peak temperature.

Mare Basalts-Elephant Moraine 87521 has induced TL peak temperatures very similar to those of Apollo mare samples, especially Apollo 12 and 15 basalts (Fig. Ia). It is possible that its slightly greater TL sensitivity compared to most Apollo mare samples reflects the presence of a highland component. At least one small highland impact melt clast has been observed in EET 87521 (Warren and Kallemeyn, 1989). Asuka 881757 also has a TL peak temperature similar to those of Apollo mare basalts, but a lower TL sensitivity, perhaps suggesting that this meteorite was heavily shocked and then rapidly cooled. Consistent with this, the feldspar is maskelynized in Asuka 881757 (Yanai and Kojima, 1991), and only traces of crystalline feldspar would account for the TL sensitivity. The impact that produced the low TL sensitivity might have been the same event that ejected the meteorite from the Moon. The low induced TL sensitivity of Y-793169 could also be interpreted in terms of shock, although petrographically it is an unbrecciated diabase (Yanai and Kojima, 1991). Distinctive plagioclase textures were thought by these authors to indicate recrystallization after maskelynization, but this process must have been minimal or the TL sensitivity would be much higher. Takeda ef al. (1993) have described this meteorite as partially maskelynitzed. The TL peak temperature for $\mathrm{Y}-793169$ indicates partially ordered feldspar and thus slower cooling than experienced by the mare basalts. Therefore, either Y-793169 experienced slower cooling in a lava flow than most mare rocks, or it experienced at least a two stage excavation history, involving a large shock event that resulted in immediate burial and slow cooling followed by a large impact event that ejected it from the surface.
Queen Alexandra Range 94281-This meteorite has been described as a basalt-rich breccia, with a composition intermediate to EET 87521 and Calcalong Creek and very similar to Y-793274 (Mason, 1995). The induced TL properties of QUE 94281 are different from other lunar meteorites, this meteorite having a fairly low induced TL peak temperature but a moderate TL sensitivity (Fig. Ia). These data may indicate that this meteorite has a significant "pristine" highland component (Fig. Ib). Alternatively, this meteorite may have experienced a significant heating event, with peak temperatures of $\sim 800^{\circ} \mathrm{C}$ (Symes et al., 1995) followed by slow cooling, which is analogous to the inferred history of Y-793169. Unlike Y-793169, however, the feldspar of QUE 94281 was not maskelynized to a significant degree, as evidenced by the relatively high TL sensitivity of this meteorite. In support of the TL data reflecting a highland component, petrographic and bulk chemical composition seem to indicate that $\sim 30 \%$ of this meteorite may be derived from highland components (Jolliff et al, 1996; Kring et al, 1996; Lindstrom et al., 1996).

Highland Rocks-The highland lunar meteorites have homogeneous induced TL properties that are consistent with their being uniform mixtures of highland impact melt rock and primitive highland material (TL properties defined from lunar soil and pristine rocks by Benoit et al., 1994,). These meteorites have a significant amount of impact glass and heavily shocked fragments (Delaney, 1990; Yanai and Kojima, 1991). The TL data suggest that MAC $88104 / 5$ is the most mature highland lunar meteorite, having a low TL sensitivity and one split with high induced TL peak temperature. The latter split is probably dominated by the recrystallized melt breccia clasts that are common in this rock (Kocberl et al., 1991). MacAlpine Hills 88105 is thought to be a less mature regolith breccia than ALHA81005 and QUE 93069 (Warren et al., 1983; Koeberl et al., 1991; Warren and Kallemeyn, 1995), but induced TL 


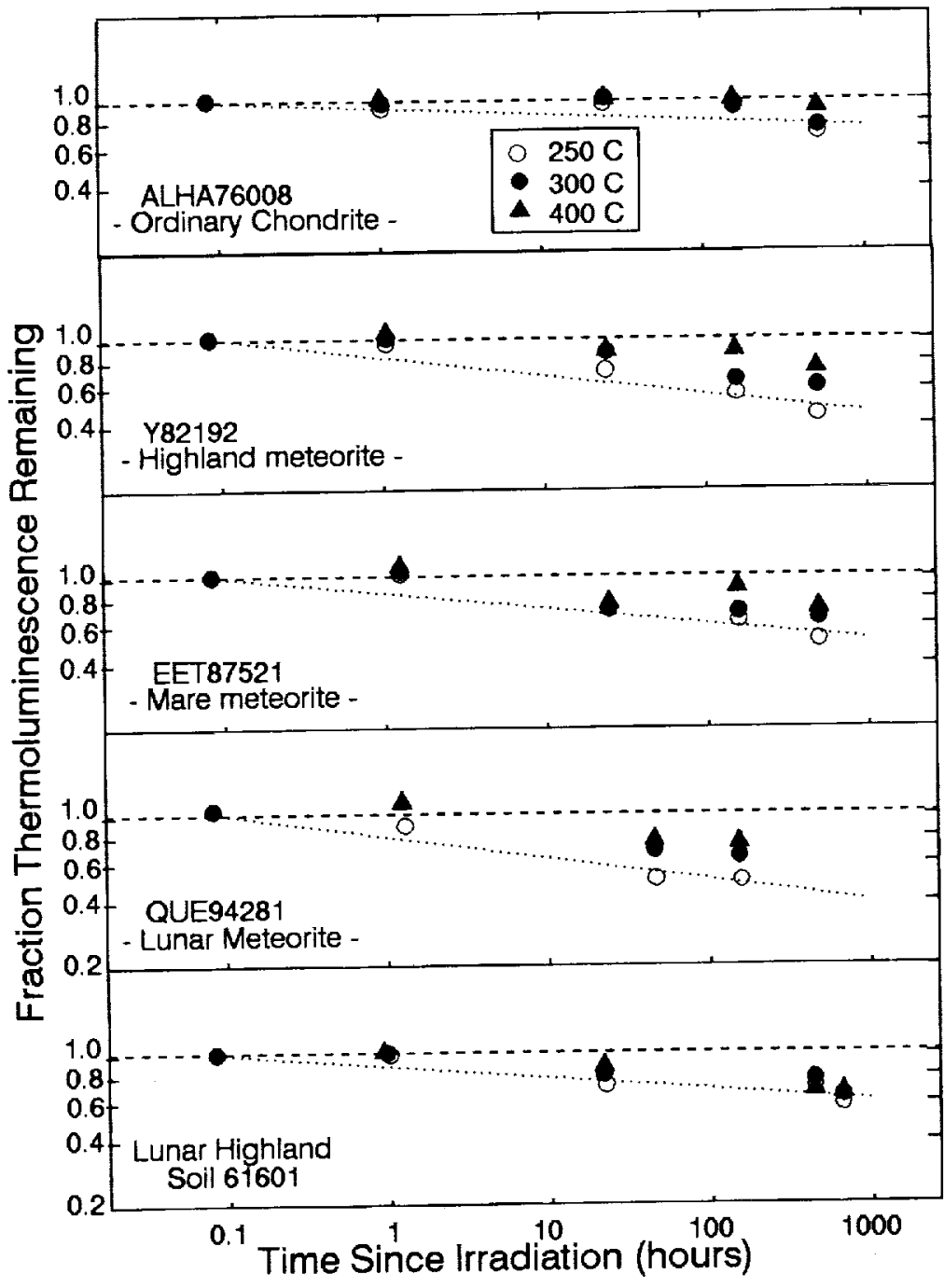

FIG. 3. Thermoluminescence remaining as a function of storage time for EET 87521, Y82192, QUE 94281, the equilibrated ordinary chondrite ALHA76008, and highlanddominated lunar soil 61501 at 250,300 , and $400{ }^{\circ} \mathrm{C}$ in the glow curve. Regression lines for the $250^{\circ} \mathrm{C}$ data are shown as dotted lines. The loss of TL throughout the glow curve for the $250^{\circ} \mathrm{C}$ data are shown as dotted lines. The loss of samples except the ordinary chondrite ALHA76008. Ordinary chondrites do not display anomalous fading but only slow thermal fading at the longest duration.

reflects the lithification event(s) as well as the regolith history of the bulk sample. Alternatively, the relatively low TL sensitivity of MAC $88104 / 5$ could reflect the presence of mare material, but this is unlikely as mare components are in very low abundance (Delaney, 1990; Koeberl et al., 1991).

\section{Natural TL.}

Natural TL, levels decrease by time- and temperature-dependent decay, and, in some cases, anomalous fading (Wintle, 1973; Sears $e t$ al., 1991a), while the only mechanism for increasing natural TL levels is exposure to ionizing radiation. Equilibrium natural TL levels are reached after $\sim 10^{5} \mathrm{a}$ in typical meteorites in the inner solar system (e.g., Fig. 4). The low natural TL levels of lunar meteorites relative to the basaltic meteorites (Fig. 2a,b) can therefore reflect heating in space, long terrestrial ages, differences in anomalous fading, or short irradiation times. Most Antarctic achondrites appear to have terrestrial ages in excess of 50,000 a (Nishii- zumi et al., 1989), but of the present samples, only MAC $88104 / 5$ has a terrestrial age significantly greater than this (Table 1). MacAlpine Hills $88104 / 5$ also has higher natural TL levels than the other lunar meteorites. The anomalous fading characteristics of ALHIA81005 (Sutton and Crozaz, 1983), MAC 88104/5 (Sears et al., 1991a) and the basaltic meteorites are very similar to those of Y-2192, EET 87521, and QUE 94281 and highlanddominated lunar soil (Fig. 3), in contrast to the equilibrated ordinary chondrites like ALH $\Lambda 76008$, that exhibit no anomalous fading. The experimental uncertainties on these data make extrapolation of anomalous fading to thousands of years difficult, but the relative rates of fading will not change. Thus, while anomalous fading is the likely cause of the low TL of basaltic achondrites compared to ordinary chondrites, neither anomalous fading nor terrestrial age can explain the low natural $\mathrm{TI}$, level of lunar meteorites compared to the basaltic meteorites.

The low natural TL values for lunar meteorites might reflect small perihelia orbits or short transit times. We have determined the TL parameters for the TL traps in ALHA81005 using a peak fitting approach (McKeever, 1980), and we have experimentally determined the doseresponse for this meteorite (sce Appendix). Allan Hills A81005 was used for this determination because of its relatively high TL sensitivity. However, limited measurements on Y-82192, EET 87521, and QUE 94281 indicate that these meteorites exhibit similar dose-reponse. From these data, we calculate the curves for build-up in natural $\mathrm{TL}$ at 250 and $400{ }^{\circ} \mathrm{C}$ in the glow curve allowing for anomalous fading (Fig. 4). These curves assume a "storage temperature" of $273 \mathrm{~K}$ and a radiation dose of $5 \mathrm{rad} / \mathrm{a}$, the latter estimate appropriate for irradiation of a meter-sized body by galactic cosmic rays (Letaw et al., 1988). Other temperatures and dose rates yield different final equilibrium TL. level and time required to reach this level but do not radically change our results. From these curves, we determine the duration of irradiation for each metcorite from the $400^{\circ} \mathrm{C}$ curve (Table 2). Assuming the meteorites were not exposed to radiation prior to lunar cjection, or that their TL levels were reset by the ejection events, these estimates equal transit times from the Moon to the Earth.

The calculated irradiation durations range from $<1000$ a to about $>100,000$ a (Table 2), but with most estimates $<15,000 \mathrm{a}$. The natural TL of Asuka 881757 and Y-82192 could be at saturation, but it is also possible that the TL levels of these meteorites were not completely reset by their ejection events. To examine this issue further, we use the more thermally-sensitive $250^{\circ} \mathrm{C}$ glow curve data. For EET 87521, MAC 88104/5, QUE 94281, and $\mathrm{Y}-793169$, the irradiation times estimated from $250^{\circ} \mathrm{C}$ in the glow curve agree well with those calculated from the $400^{\circ} \mathrm{C}$ data, but for ALHA81005, Asuka 881757, and Y-82192 the irradiation times estimated from the natural TL at $250^{\circ} \mathrm{C}$ in the glow curve are much less than those estimated from natural TL at $400^{\circ} \mathrm{C}$. Apparently, either the natural TL at $400^{\circ} \mathrm{C}$ was only partially reset by cjection from the Moon, or these samples were heated in space. In the former case, it should be noted that the equilibrium natural TL level in lunar soils for glow curve temperatures in excess of $\sim 200^{\circ} \mathrm{C}$ is $\sim 6 \mathrm{krad}$ for samples between $\sim 5$ to $100 \mathrm{~cm}$ beneath the surface (Benoit and Chen, 1996). Samples from lesser and greater depths 


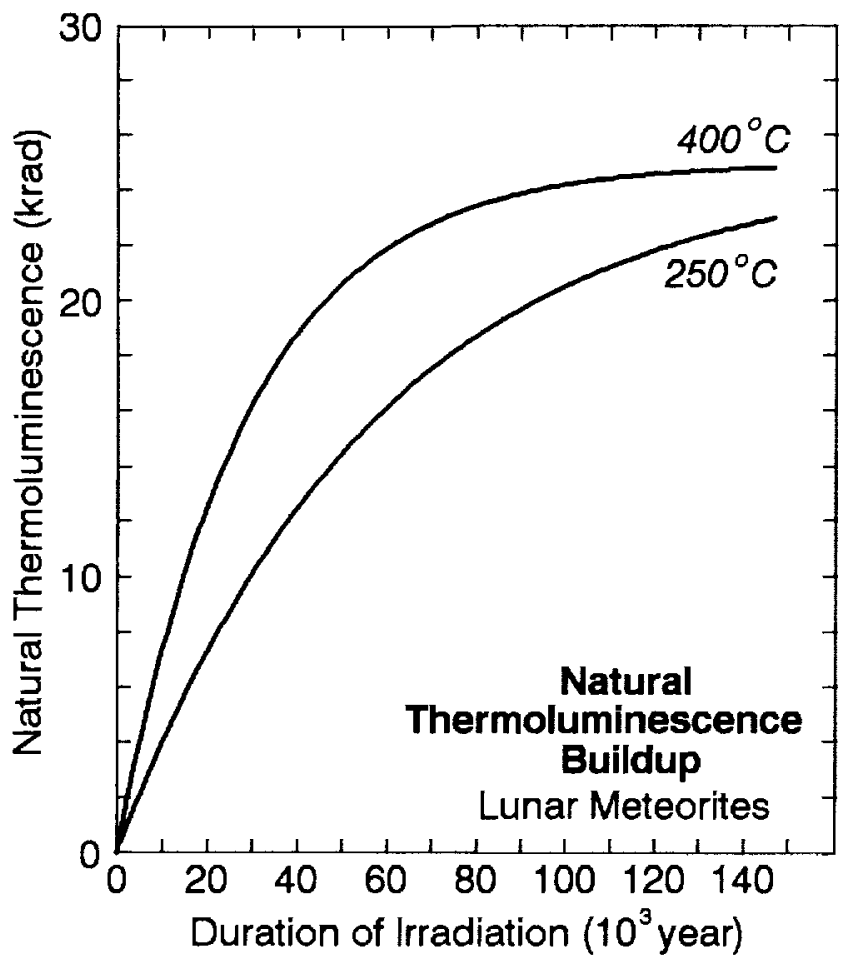

Fig. 4. Natural TL buildup at 250 and $400^{\circ} \mathrm{C}$ in the glow curve as a function of time assuming no precxisting TL. This curve is calculated assuming a saturation TL level of $25 \mathrm{krad}$ (Fig. 2), TL trap properties determined from glow curves (see Appendix), the observed rates of anomalous fading for lunar meteorites (Fig. 3), and a radiation dose of $5 \mathrm{rad} / \mathrm{a}$

exhibit lower natural TL levels, due to the diurnal heat pulse and radiation attenuation, respectively. Therefore, if the $\mathrm{TL}$ levels of these meteorites were not reset by the ejection event, they should have apparent exposure times of $\sim 6,000 \mathrm{a}$, with any exposure in space increasing this apparent exposure time (Fig. 4). The apparently rapid transit times are generally consistent with the orbital calculations of Gladman et al. (1996). Their results indicate that meteorites from the Moon usually are captured by the Earth shortly after their production or break away from the Earth-Moon system and experience orbital evolution leading to ejection from the solar system or eventual impact with planets.

If some of these samples were heated in space, as indicated by discrepancies between irradiation duration estimates at different glow curve temperatures, the most likely heat source would be close approach to the Sun, as was suggested by Sutton (1986) for Y-82192. Using our experimentally derived parameters for $\mathrm{TL}$ at $250^{\circ} \mathrm{C}$, and a black body approximation for solar heating (e.g., Melcher, 1981), we estimate that AI.HA81005 and Asuka 881757 would have had perihelia $<0.5 \mathrm{AU}$, while $\mathrm{Y}-82192$ had a perihelion of $\sim 0.7 \mathrm{AU}$.

There are a number of basaltic achondrites that have natural TL levels similar to those of lunar meteorites (Fig. 3). We have previously interpreted the data for these basaltic achondrites as indicative of reheating (Sears et al., 1991a). This interpretation is supported by the cosmic-ray cxposure ages of basaltic achondrites, which typically are $>5 \mathrm{Ma}$ and preclude short radation exposure (Eugster and Michel, 1995). Unlike lunar meteorites, the basaltic achondrites generally have been exposed to cosmic radiation in space long enough to reach equilibrium TL levels, and thus their TL levels reflect their thermal environment rather than irradiation duration.
TABLE 2. Transit times for lunar meteorites from cosmogenic nuclide abundances and thermoluminescence.

\begin{tabular}{lccc}
\hline Meteorite & $\begin{array}{c}\text { Cosmogenic } \\
\text { "Transit" Time } \\
(\mathrm{Ka})^{*}\end{array}$ & $\begin{array}{c}\text { Thermoluminescence } \\
\text { "Transit" Time } \\
400^{\circ} \mathrm{C}(\mathrm{Ka})^{\dagger}\end{array}$ & $\begin{array}{c}\text { Ejection } \\
\text { Time } \\
(\mathrm{Ka})^{\ddagger}\end{array}$ \\
\hline ALHA81005 & $<100$ & $10 \pm 5^{\S}$ & $\sim 25$ \\
A881757 & $900 \pm 100$ & $>100^{\S}$ & $>125 / \sim 25$ \\
EET 87521 & $<100$ & $<1$ & $\sim 20$ \\
MAC 88104/5 & $<200$ & $12 \pm 3$ & $\sim 240$ \\
QUE 94281 & - & $1.0 \pm 0.2$ & - \\
Y-793169 & $1,100 \pm 200$ & $6 \pm 3$ & -30 \\
Y-82192 & $10,800+600$ & $>45^{\S}$ & $>120 / \sim 90$
\end{tabular}

${ }^{*}$ Based on ${ }^{10} \mathrm{Be}$ and cosmogenic noble gas abundances. Data from Eugster (1989), Vogt et al. (1991), Thalmann and Eugster (1994), and Nishiizumi ef al. (1995).

tBased on an irradiation temperature of $273 \mathrm{~K}$ and a radiation dose of 5 $\mathrm{rad} / \mathrm{a}$. Uncertainties are based on analytical precision.

$\ddagger$ Transit time (estimated from TL) + terrestrial age (Table 1)

$\$$ May reflect preejection irradiation. Apparent transit times based on $250{ }^{\circ} \mathrm{C}$ in the glow curve are $<1,000$ a for ALHA8I005 and Asuka 881757 and $11 \pm 2$ for Y-82192

The transit time estimates from natural TL for Asuka 881757, $Y-793169$, and $Y-82192$ are significantly smaller than those derived from cosmogenic nuclide abundances. Of course, both TI and cosmogenic transit time estimates are subject to many assumptions about the irradiation and thermal history of these meteorites, but the quoted uncertainties refer only to analytical precision. For instance, although Nishiizumi et al. (1992) suggested a transit time of $0.9 \pm 0.1$ Ma for Asuka 881757 based on cosmogenic nuclide abundances, they noted that a history involving $2 \mathrm{Ma}$ of irradiation on the lunar surface and a transit time of $<0.1$ Ma was equally consistent with the data. Cosmogenic nuclide data for QUE 93069 can be interpreted likewise as reflecting a long transit time or a long lunar surface exposure history (Nishiizumi et al., 1995).

If we interpret the TL data for ALHA81005 and Asuka 881757 as reflecting short transit times and add the TL-derived transit times to the terrestrial ages for lunar meteorites (Table 1), we can calculate ages for the events that ejected them from the Moon (Table 2). Two meteorites, MAC 88104/5 and Y-82192, appear to have been produced during separate ejection events $\sim 240$ and $90 \mathrm{Ka}$, respectively, while the other meteorites were derived from events $<50 \mathrm{Ka}$.

\section{CONCLUSIONS}

Our induced TL, data indicate that, despite their rather extreme transport history, lunar meteorites had thermal histories very similar to those of Apollo lunar samples of similar petrography. The highland-dominated lunar meteorites, all breccias or regolith breccias, can be considered as mixtures of primitive highland material and local impact melt. These meteorites can be considered more thermally mature than "pristine" lunar samples and bulk highland-dominated soil, and MAC $88104 / 5$ may be the most impact processed in this suite. Mare lunar meteorites share the fast cooling history of marc lunar samples, a possible exception being Y-793169 which may have had most of its feldspar destroyed during a large impact followed by some recrystallization under slow cooling conditions, or the sample may have cooled in a fairly thick lava flow.

Our natural TL data can be interpreted in terms of transit time for these meteorites. We find that most lunar meteorites have very short transit times, generally not more than a few thousand years 
and $<1,000$ a in the case of EET 87521. Lunar meteorites EET 87521, MAC 88104/5 and Y-793169 appear to have had simple one stage irradiation histories but the TL of ALHA81005, Asuka 881757, and Y-82192 either reflects preserved irradiation on the lunar surface or a thermal event, such as small perihelia orbits.

Acknowledgements-We wish to thank Ludolf Schultz, Steve Sutton, and Paul Warren for their comments on this paper. We also wish to thank Robbie Score, the Meteorite Working Group of NASA and K. Yanai (NIPR, Japan) for the samples used in this study. This study funded by NASA grants NAGW 3519 and NAGW 9-81 and NSF grant DPP 91552I

Editorial handling: L. Schultz

\section{REFERENCES}

BATCHELOR J. D (1992) A luminescence study of metamorphism, brecciation, and shock in extraterrestrial basalts: (Eucrites, diogenites, howardites, mesosiderites, and the Moon). Ph.D. thesis, Univ. Arkansas. $194 \mathrm{pp}$.

BATCIELOR J. D. AND SEARS D. W. G. (1991) Thermoluminescence contraints on the metamorphic, shock, and brecciation history of basaltic meteorites. Geochim Cosmochim. Acta 55, 3831-3844.

BENOIT P. H. AND CHEN Y. (1996) Galactic cosmic-ray-produced thermoluminescence profiles in meteorites, lunar samples and a terrestrial analog. Rad. Meas. 26, 281-289.

BeNOIT P. H., SEARS D. W. G. AND MCKEEVER S. W. S. (1991) The natural thermoluminescence of metcorites II. Meteorite orbits and orbital evolution. Icarus 94, 311-325

BenoIT P. II., CHEN Y. AND SEARS D. W. G. (1994) Primitive material in lunar highland soils (abstract). Lunar Planet. Sci. 25, 97-98.

DELANEY J. S. (1990) Preliminary petrographic data for MAC 88105: Anorthositic microbreccia (abstract). Lunar Planet Sci. 21, 273-274.

Durrani S. A. KHAZAL K. A. R. AND Ali A. (1977) Temperature and duration of the shadow of a recently-arrived lunar boulder. Nature 266, $411-415$.

EUGSTER O. (1989) History of meteorites from the Moon collected in Antarctica. Science 245, 1197-1202.

EUGSTER O. AND MICHEL TH. (1995) Common asteroid break-up events of eucrites, diogenites, and howardites and cosmic-ray production rates for noble gases in achondrites. Geochim. Cosmochim. Acta 59, 177-199.

Geake J. E., Walker G., TEl.fer D. J. AND Mills A. A. (1977) The cause and significance of luminescence in lunar plagioclase. Phil. Trans. Roy. Soc. Lond. A. 285, $403-408$.

Gladman B. J., Burns J. A., Duncan M., LeE P. and Levison H. F. (1996) The exchange of impact ejecta between terrestrial planets. Science 271, 1387-1392.

Guimon R. K., KECK B. D., WeEkS K. S., DEHART J. and SEARS D. W. G. (1985) Chemical and physical studies of type 3 chondrites-IV: Annealing studies of a type 3.4 ordinary chondrite and the metamorphic history of metcorites. Geochim. Cosmochim. Acta 49, 1515-1524.

GUIMON R. K., SYMES S. J. K., SEARS D. W. G. AND BENOIT P. II. (1995) Chemical and physical studies of type 3 chondrites XII: The metamorphic history of $\mathrm{CV}$ chondrites and their components. Meteoritics 30, 704-714.

haq M., hasan F. A., Sears D. W. G., Moore C. B. and Lewis C. F. (1989) Thermoluminescence and the origin of the dark matrix of Fayetteville and similar metcorites. Geochim. Cosmochim. Acta 53, $1435-1440$

HARTMETZ C. P. AND SEARS D. W. G. (1987) Thermoluminescence and Xray diffraction sutdies of annealed oligoclase (abstract). Lunar Planet. Sci. 21, 461-621.

HoYt H. P., JR., MiYajima M., Waleir R. M., Britton D. and Kardos J. L. (1971) Radiation dose rates and thermal gradients in the lunar regolith: Thermoluminescence and DTA of Apollo 12 samples. Proc. Lunar Planes $S_{\subset} i$ Conf 2nd, 2245-2263.

JOLliFF B. L.. ROCKOW K. M. AND KOROTEV R. L. (1996) QUE 94281: Shallow plutonic VI.T components and highlands components (abstract). Lunar Planet. Sci. 27, 615-616.

KOEBERL C KURAT G. AND BRANDSTÁTTER F. (1991) MAC 88105 - A regolith breccia from the lunar highlands: Mineralogical, petrological, and geochemical studies Geochim Cosmochim. Acta 55, 3073-3087.

KRING D A. HILL D. H. AND BOYNTON W. V. (1996) A glass-rich view of QUE 94281 , a new meteoritic sample from the mare region of the Moon (abstract). Lunar Planet. Sci. 27, 707-708
Letaw J. R.,, Silberberg R. AND TSao C. H. (1988) Galactic cosmic radiation doses to astronauts outside the magnetosphere. In Terrestrial Space Radiation and its Biological Effects, (eds. P. D. McCormack, C. E. Swenberg and II. Bucker), pp. 663-673. Plenum Press, New York, New York.

LINDSTROM M. M., ED. (1989) Antarctic Meteorite Newsletter. 12(2), Johnson Space Center, Houston, Texas

LindSTROM M. M., MitTlefehldt D. W., Morris R. V. And Martinez R. R. (1996) QUE 94281, a glassy basaltic-rich lunar meteorite similar to Y-793274 (abstract). Lunar Planet. Sci. 27, 761-762.

MASON B. (1995) In Antarctic Meteorite Newsletter, 18(2), p. 21. Johnson Space Center, Houston, Texas.

MCKEEVER S. W. S. (1980) The analysis of thermoluminescence glowcurves from meteorites. Mod. Geol. 7, 105-I14.

MELCHER C. L. (1981) Thermoluminescence of meteorites and their orbits. Earth Planet. Sci. Lett. 52, 39-54.

NisHIZUMI K., ELMORE D. AND KUBIK P. W. (1989) Update on terrestrial ages of Antarctic meteorites. Earth Planet. Sci. Lett 93, 299-313.

Nishizumi K., ARnOLd J. R., CAFFE M. W., Finkel R. C., SOUthon J. AND REEDY R. C. (1992) Cosmic ray exposure histories of lunar meteorites Asuka 881757, Yamato 793169, and Calcalong Creek (abstract). NIPR Symp. Antarct Meteor. 17, I29-132.

NishiIZUMI K., CAFFEE M. W., FINKEL R. C. AND REEdy R. C. (1995), Exposure history of lunar meteorite QUE 93069 (abstract). Lunar Planet Sci. 26, 105I-1052.

Sears D. W G. and Hasan F. A (1986) Thermoluminescence and Antarctic metcorites. In Workshop on Antarctic Meteorites (eds. J. Annexstad, L. Schultz, and H. Wänke, eds), pp. 83-100. LPI Tech. Rpt. 86-01, Lunar and Planetary Institute, Ilouston, Texas.

Sears D. W. G., Benoit P. I., SeARs H., Batchelor J. D. AND Symes $S$ (1991a) The natural thermoluminescence of meteorites: III. Lunar and basaltic meteorites. Geochim. Cosmochim. Acta 55, 3167-3180.

Sears D. W. G. Hasan F. A., Batchelor J. D. and lu J. (1991b) Chemical and physical studies of type 3 chondrites-XI: metamorphism, pairing, and brecciation of ordinary chondrites. Proc. Lunar Planet. Sci.Conf. 21st, 493-512.

SIPPEL R. F. AND SPENCER A. B. (1971) Luminescence petrography and properties of lunar crystalline rocks and breccias. Proc. Lunar Planet. Sci. Conf. 3rd, 2413-2426.

SUTTON S. R. (1986) Thermoluminescence of lunar meteorite Yamato82192. Evidence for a small perihelion orbit. Meteoritics 21, 520-521.

SUTTON S. R. AND CROZAZ G. (1983) Thermoluminescence and nuclear particle tracks in ALHA 81005: Evidence for a brief transit time. Geophys. Res. Lett. 10, 809-812.

Symes S. J. K., BENOIT P. H., SEARS D. W. G., AND MCKAY D. S. (1995) The luminescing lunar regolith (abstract). Lunar Planet. Sci. 26, $1387-$ 1388.

TAKEDA H., ARAI T. AND SAIKI K. (1993) Mineralogical studies of lunar meteorite Yamato-793169, a mare basalt. Proc. NIPR Symp. Antarct. Meteor. 6th, 3-13.

THALMANN CH. AND EUGSTER O. (1994) Cusmic ray exposure history of two basaltic lunar meteorites: Asuka 881757 and Yamato 793169 (abstract). Meteoritics 29, 540 .

VOGT S., Fink D., KLEIN J., MidDleton R., DOCKHORN B., KORSCHineK G., NOLETE E. AND IIERZOG G. F. (1991) Exposure history of the lunar meteorites: MacAlpine Hills 88104, MacAlpine Hills 88105, Yamato 791197 and Yamato 86032. Geochim. Cosmochim. Acta 55, 31573165

WARREN P. II. AND KALLEMEYN G. W. (1989) Elephant Moraine 87521: The first lunar metcorite composed of predominently mare material. Geochim Cosmochim Acla 53, 3323-3300.

WARREN P. H. and KaLlemeYn G. W. (1991) The MacAlpine Hills lunar meteorite and implications of the lunar meteorites collectively for the composition and origin of the Moon. Geochim. Cosmochim Acta 55, 3123-3138

WARREN P. H. AND KaLLEMEYN G. W. (1995) QUE 93069: A lunar meteorite rich in HASP glasses (abstract). Lunar Planet. Sci. 26, 14651466

WARREN P. H., TAYLOR G. J. AND KEIL K. (1983) Regolith breccia Allan Hills A81005: Evidence of lunar origin, and petrography of pristine and nonpristine clasts. Geophys. Res. Lett 10, 779-782.

WINTLE A. (1973) Anomalous fading of thermoluminescence in mineral samples. Nature 245, 143-144.

YANAI K. AND KOIMA H. (1991) Varieties of lunar meteorites recovered from Antarctica. Proc. NIPR Symp. Antarct. Meteor. 4th, 70-90 


\section{APPENDIX}

The characteristics of the "trap" populations contributing to the natural TL of ALHA81005 were determined using a peak fitting procedure (McKeever, 1980). We find that the natural TL of ALHA81005 is dominated by two trap populations with maximum peak temperatures of 250 and $290^{\circ} \mathrm{C}$. There is some overlap of these traps, and the $290^{\circ} \mathrm{C}$ trap population contributes to TL up to $400^{\circ} \mathrm{C}$ in the glow curve. We estimate that the trap depths $(\mathrm{E})$ and frequency factors $(s)$ are 1.54 and $1.72 \mathrm{eV}$, and $1 \times 10^{13}$ and $9 \times 10^{12}$ (seconds) ${ }^{-1}$ for the 250 and $290^{\circ} \mathrm{C}$ traps, respectively. Uncertainties on these estimates are $-10 \%$. In comparison, the natural TL of ordinary chondrites is dominated by two trap populations at glow curve temperatures of -250 and $400{ }^{\circ} \mathrm{C}$ with trap depths of 1.3 and $1.5 \mathrm{eV}$ and frequency factors of $9 \times 10^{12}$ and $1.6 \times 10^{10}$ (seconds) $)^{-1}$ (McKeever, 1980).
In order to determine the TL build-up curve for the trap populations (e.g., Fig. 4), it is necessary to determine experimentally the radiation dose required to fill them to equilibrium levels. We irradiated a sample of ALHA8 1005 for times ranging from $5 \mathrm{~min}$ to $24 \mathrm{~h}$ in a ${ }^{90} \mathrm{Sr}$ beta cell and measured their TL. From these data, we find that the radiation dose necessary to achieve equilibrium TL levels in the laboratory is -200 $\mathrm{krad}$ and $120 \mathrm{krad}$ for the 250 and $290{ }^{\circ} \mathrm{C}$ traps, respectively. Note that these doses do not include inefficiencies in converting dose to $T L$, nor do they include the effects of anomalous fading and are thus not equivalent to measured saturation TL levels for lunar meteorites. 


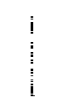

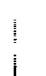

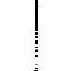

